\title{
Model of e-commerce cloud warehouse grading based on mass simulation data
}

WANG Fan ${ }^{1 *}$, WANG Yan-Li ${ }^{1}$, LIU Zhi-Jie ${ }^{1}$, CUI Xiao ${ }^{2}$, ZHANG Peng ${ }^{3}$

${ }^{1}$ Department of Express Delivery and Logistics, Shijiazhuang Posts and

Telecommunications Technical College, Shijiazhuang, Hebei, 050021, China

${ }_{2}^{2}$ Accounting institute, Shijiazhuang Vocational College of Finance \& Economics, Shijiazhuang, Hebei, 050051, China

${ }^{3}$ School of Management, University of Bath, Bath, BA27AY, United Kingdom.

*Corresponding Author, email: coolbase@163.com

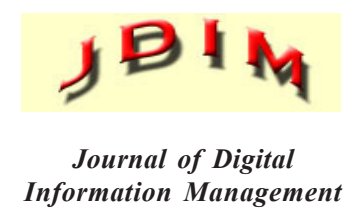

ABSTRACT: E-commerce cloud warehouse is a logistic service model developed to meet e-commerce demands. The model is characterized by multi-site warehousing, big data prediction, accurate stock, and nearby distribution. A set of unified management standards must be established to effectively address the difficulty in ecommerce cloud warehouse management. For the convenience of quantitative grading management of branch warehouses, the method for confirming ecommerce cloud warehouse grading based on mass simulation data analysis was proposed in this paper. The discrete event simulation model was built, the simulation experiment was designed, and the mass experimental data were analyzed and integrated to finally obtain the model of e-commerce cloud warehouse grading. The effectiveness of the grading model was also verified. Analysis results suggest that historical data cannot guarantee adequate big data size and sufficiently high data accuracy for the issues of ecommerce cloud warehouse grading. Thus, experimental data must be obtained by building a discrete event simulation model. The validity and universality of the simulation model are necessary to ensure the rationality of experimental data. Through simulation modeling, simulation experiment design, and experimental data mining, the quantitative standards for e-commerce cloud warehouse grading can be obtained. Verification results show that the quantitative grading results are consistent with the experience-based grading results. This research proves the feasibility of obtaining the quantitative standards for e-commerce cloud warehouse grading based on mass simulation experimental data. The proposed grading model is suitable for e-commerce cloud warehouses of different industries.

Subject Categories and Descriptors

J.1 [Computer Applications]: Administrative Data Processing; I.6.6 [Simulation and Modeling]: Simulation Output Analysis

\section{General Terms}

Warehouse, Information Management, Big Data, Simulation

Keywords: E-Commerce Cloud Warehouse, Mass Data, Discrete Event Simulation

Received: 21 April 2016, Revised: 27 June 2016, Accepted: 3 July 2016

DOI: $10.6025 / \mathrm{jdim} / 2016 / 14 / 5 / 311-321$

\section{Introduction}

The development of e-commerce and online to offline model has made rapid, efficient, and accurate delivery an essential customer experience to enterprises and customers. Rapid delivery of goods relies on integration of "warehousing-transportation-distribution" and building of a flat supply chain. In response to such development needs, e-commerce cloud warehouse has been developed.

The concept of "cloud warehouse" has originated in China 
and has not been given an official definition in English. Many existing concepts are similar to "cloud warehouse," such as "cloud storage" $[1,2]$ and "cloud data warehouse" [3-5] in the computer field, and "cloud muster warehouse" in the financial field $[6,7]$. Considering the close connection between cloud warehouse and e-commerce, the term, "e-commerce cloud warehouse," was adopted in this paper to differentiate the concept from other similar ones.

E-commerce cloud warehouse is a "multi-site warehousing and nearby distribution" service model and relies on cloud technology, modern management methods, and warehousing facilities. The model can be used in increasing the efficiency of the entire supply chain through data analysis, regional collaboration, network-wide allocation, and other strategies.

According to the model of e-commerce cloud warehouse, enterprises must build branch warehouses of different scales throughout a country, stock up precisely based on big data prediction, and emphasize on operation efficiency and fine management [8]. After receiving an order from a customer, enterprises deliver goods from the branch warehouse nearest to the customer, thereby guaranteeing efficient delivery and good customer experience. At present, China's e-commerce cloud warehouse service model is introduced in the development period where big data is regarded as productivity. Data analysis can help optimize the warehouse distribution, delivery route selection, and logistics supply chain of enterprises [9].

The e- commerce cloud warehouse has attracted attention from numerous corporate users because of its advantages and value over the traditional warehouse. However, multisite warehousing increases difficulty in management. Multi-site branch warehouses of many enterprises are often under extensive management during practical operation because of the lack of a set of unified management modes and standards. In the long term, this phenomenon inevitably causes disorder and inefficiency in management.

In an ideal model of e-commerce cloud warehouse, enterprises conduct standard management of various branch warehouses based on warehouse grading. Branch warehouses of different grades require various management standards. Every branch warehouse is built and managed according to its grading results. Enterprises evaluate the performance of branch warehouses in accordance with preset KPI indexes. By doing so, enterprises can dominate planning and operation standard formation for every warehouse. They can also improve their fine management level and executive capability.

To achieve such an ideal model, the confirmation of warehouse management grading based on the subjective experiences of management personnel must be first transferred to quantitative grading based on analysis of objective data.
In this paper, Group A was used as an example in introducing the construction idea and modeling process of the model of e-commerce cloud warehouse grading. The proposed grading model applies to e-commerce cloud warehouse grading issues of other industries.

The research provides theoretical bases and practical experiences for transforming the traditional e-commerce cloud warehouse management model to a data-based, standardized, and fine management model.

\section{Literature Review}

\subsection{Warehouse management}

In warehouse management, the traditional logistics industry mainly adopts the single-warehouse management model instead of unified grading standards for multiple warehouses. To adopt single-warehouse management model is decided by characteristics of the logistics warehouse, chiefly few delivery categories, large delivery batches, and less strict time limits. Therefore, theoretical research on warehouse management of the traditional logistics industry seldom involves the issue of unified grading of multiple warehouses supervised by the same enterprise. Meanwhile, e-commerce cloud warehouse has originated from the e-commerce and express service industry and follows warehouse management [10]. Ecommerce cloud warehouse is characterized mainly by multiple delivery categories, small delivery batches, high delivery frequency, and strict time limits. Moreover, the difficulties in warehouse management by e-commerce cloud warehouse are more than those in warehouse management by traditional logistics [10].

\subsection{E-commerce cloud warehouse}

Chinese scholars concentrate on investigating the model design and warehouse management strategies of ecommerce cloud warehouse [6-9]. Few of them explore data management and big data analysis techniques.

HE [6] proposed the concept of "cloud muster warehouse" in the field of financial supply chain. On the basis of cloud muster warehouse, PAN [7] established the loan pricing model for supply chain finance. However, these researches are confined to the financial field and present limited application to e-commerce cloud warehouse. LI [8, 9] introduced the concept and advantages of e-commerce cloud warehouse and summarized three e-commerce cloud warehouse models. Nevertheless, the study failed to comprehensively examine the issue.

The term "e-commerce cloud warehouse" has not been introduced to other countries yet. "General-branch warehouse" is a concept whose meaning is similar to ecommerce cloud warehouse, but relevant theoretical research is still lacking.

\subsection{Discrete event simulation}

Discrete event simulation models involved in literature are built based on specific circumstances [11-15]. 
Zhang [11] proposed a higher level agent-based emulation framework, and tested distribution centre level algorithms by an emulation model for a distribution centre. Wasusri [12] built a discrete event simulation model using ARENA to find the best picking strategy. Bleifus [13] described the storage and picking technology, the stages of the simulation project and the benefits of both. Gagliardi [14] presented a simulation model framework for unit-load automated storage and retrieval systems able to cope with most of the features found in industrial settings. Wang [15] explored methods of simulation and related problems combining the actual improvement of a mail processing center of EMS, and pointed the concrete process.

A unified model for problem description and grading of multiple warehouses has not been developed yet.

\subsection{Big data}

The concept of big data has been explored from different perspectives.

Mayer-Schonberger [16] argued that the big data technique allows certain degree of inaccuracy. Thus, all data must be analyzed and processed instead of following the shortcut of sampling survey. Moreover, the correlation reflected by big data can counteract the negative influence of incorrect data. He also emphasized that the simple algorithm based on big data is more effective than the complex algorithm based on small data. TU [17] believed that collection and scientific analysis of data are essential to decision making. Data in China are weak in credibility, poor in quality, and inconsistent in definition. In response to the problem, the cultural atmosphere of "managing and making decisions based on data" must be advocated. Ian Ayres [18] regarded regression analysis as an efficient way for big data processing and listed a few successful cases adopting regression analysis for big data processing. Random experiment has become an increasingly important data decision-making tool; thus, analysis of random experimental data is more effective than that of historical data. The basic procedures of big data processing are as follows: first, randomly draw samples; second, control the single variable and conduct relevant experiment; third, analyze test data and verify which method is effective. Artificial intervention is necessary in most cases.

Ma [19], using regression, designed leveraging methods under a subsampling framework to visualize the big data. Berberidis [20] pointed out that a significant percentage of the data accrued can be omitted to reduce the complexity of large-scale linear regressions. And also, he put forth a task of joint censoring and estimation to solve large-scale linear regressions in a centralized setup. $\mathrm{Hu}$ [21] summarized the applications of big data in intelligent warehousing, including warehouse location, warehouse layout and warehouse supervision. But no quantitative analysis was given in his paper. Zhong [22] introduced an approach to visualize the RFID-enabled shopfloor logistics big data in cloud manufacturing to support advanced decision-makings.

In summary, scholars at home and abroad seldom study the grading-based management of e-commerce cloud warehouse. Some of these scholars have provided theoretical and practical supports but these methods are still insufficient.

Unified quantitative grading standards for multiple warehouses have not been established yet, and research using mass simulation data in conducting standard warehouse construction is lacking. Therefore, in this paper, a model of e-commerce cloud warehouse grading based on the analysis of mass simulation data was proposed by referring to the idea of big data processing and the modeling experiences of discrete event simulation cases.

The rest of this study is organized as follows. The third part mainly introduces the research background and the modeling strategy. The simulation model is built to construct the mapping relationship. Then, the simulation experiment is designed. According to experimental results, the linear regression equation is built. The fourth part elaborates the modeling procedures and analyzes the model results. Conclusions are summarized in the fifth part.

\section{Methodology}

\subsection{Research background}

Group A is a cross-border company specializing in producing high-quality consumer goods of multiple series, including nutrition and healthcare products, cosmetics, and personal care materials. It has built 22 branch warehouses in China under the cloud warehouse model. The equipment layout, personnel arrangement, and storage location assignment of these branch warehouses are all based on subjective experiences. A specific set of quantitative standards or standardized management modes has not been introduced yet. Goods storage style of branch warehouses can be divided into three kinds, namely, ground storage, rack storage, and mixed stack. In ground storage, all goods are stacked on the ground with warehouse-in and warehouse-out managed artificially. In rack storage, all goods are stacked on shelves with warehouse-in and warehouse-out managed by devices, such as forklifts. In mixed stack, the former two stack styles are combined to stack some goods on the ground and other goods on shelves.

Comprehensively considering warehouse-out quantity, stock quantity, customer demands, unit land rental, staff member salary, equipment cost, and working efficiency is necessary to realize standard and fine management of branch warehouses. The optimal management grade for a branch warehouse can be obtained based on certain model and calculation. Personnel arrangement, warehouse facilities, order picking equipment, working mode, and other standards can be designed for the branch warehouse according to its management grade. In this 
paper, the model of e-commerce cloud warehouse grading was proposed to achieve the above goal.

\subsection{Modeling strategy}

This research attempted to simulate branch warehouses with the discrete event simulation system. The simulation experiment was conducted to achieve mass experimental data. Through data fitting, the correlation between specific branch warehouse indexes and branch warehouse management grade was obtained.

The analysis process does not adopt backward induction but infers unknown results based on known conditions and through gradual deductive reasoning. "Unknown results" refer to the correlation between specific indexes and branch warehouse management grades. Meanwhile, "known conditions" refer to currently available data and the data that can be generated therefrom.

The modeling process consists of four steps:

Step 1: Confirm which data are available and which data can be easily calculated;

Step 2: Consider whether unknown results can be inferred based on the above data and which essential data are still required;

Step 3: Generate necessary data based on existing data using system simulation;

Step 4: Conduct linear regression analysis of simulation experimental data, and build the correlation between data and unknown results.

The specific analysis process includes five steps, namely, parametric analysis, mapping construction, mapping verification, simulation experiment, and formula confirmation. Among them, parametric analysis corresponds to Step 1 and Step 2; mapping construction and verification correspond to Step 3; simulation experiment and formula confirmation correspond to Step 4.

\subsection{Necessary hypothesis}

A few hypotheses must be made for the model to simulate different branch warehouses based on different parametric settings and guarantee the universality of the model.

H1: Various branch warehouses can finish standardized transformation to guarantee homogeneity of their characteristics;

H2: Various branch warehouses can popularize the management information system to lay a foundation for implementing fine management;

H3: Utilization rate of the warehouse volume in which goods are stacked on the ground is 55\%;

H4: Various branch warehouses have transformed the current area-based management standards. Areas excluding the normal temperature and constant temperature areas are cancelled. The normal temperature and constant temperature areas account for $80 \%$ and $20 \%$, respectively. The two areas categorize all items into A, B, and $C$ according to their warehouse-out quantity. The warehouse-out quantities of Category A, B, and C account for $60 \%, 20 \%$, and $20 \%$ of the total, respectively.

\subsection{Parametric analysis}

According to the mapping idea, four types of parameters were summarized for the model based on known conditions. These parameters are independent variables, dependent variables, constants, and correlation variables. Among them, independent variables, constants, and correlation variables are already known while dependent variables are unknown. These known variables can be used in calculating unknown variables via certain operation.

\subsubsection{Independent variable}

In this paper, independent variables refer to major judgment indexes to confirm grading of branch warehouses. Warehouse management personnel generally consider stock quantity, warehouse-out quantity, average staff member salary, and land rental when designing or exchanging management modes. Therefore, these four factors were set as independent variables and were expressed as follows:

$w$ - Stock quantity

$x$ - Warehouse - out quantity

$y$ - Average staff salary

$z$ - Unit land rental

\subsubsection{Constants}

Constants refer to corresponding management modes of branch warehouses of different grades. They correspond to the grading of different branch warehouses. According to its practical situations, Group A has the following three management modes:

1. Ground storage + Manual work

2. Ground storage + manual work

(Category A and Category B);

Rack storage + Forklift

(Category C)

3. Rack storage + Forklift

In Plan 1 (Management Mode 1 ), all goods are stacked on the ground and picked manually.

In Plan 2, the pallet-based rack storage and ground storage are combined. The pallet-based rack storage is adopted for goods of Category $C$ while ground storage is for goods of Category A and Category B.

In Plan 3, pallet rack storage is adopted for all goods and 
these goods are picked by forklifts.

Management modes vary in different industries, but the modeling strategy is universal. Regardless of the industry, particular problems can be solved through the later mapping construction process as long as its management modes are summarized to form constants.

\subsubsection{Dependent variables}

Dependent variables refer to comparison bases of different plans, and the core factors of these variables are working efficiency and cost. High efficiency results in high performance while low cost translates to high performance. Among them, cost can be subdivided into many items. The dependent variables in this research are as follows:

$F_{1}$ - Total staff salary

$F_{2}$ - Warehouse rental

$F_{3}$ - Forklift purchase cost

$F_{4}$ - Forklift maintenance cost

$F_{5}$ - Rack purchase cost

$F_{6}$ - Rack maintenance cost

$\mathrm{F}_{7}$ - Working efficiency (warehouse-out quantity processed by every staff member within unit time)

Comparing different plans based on the above dependent variables is difficult because of the following reasons. First, the work quantity is large. Second, the judgment results of different dependent variables may be contrary to one another. Therefore, the dependent variables must be integrated as follows:

$$
F=\eta\left(F_{1}, F_{2}, \cdots, F_{7}\right)
$$

Dependent variable $F$ was adopted as the only judgment standard. The value corresponding to every management mode can be compared to confirm the optimal management mode. By comprehensively considering various factors, the formula to calculate dependent variables was confirmed. The formula is as follows:

$$
F=\frac{F_{7}}{0.017 \times\left(F_{3}+F_{5}\right)+\left(F_{1}+F_{2}+F_{4}+F_{6}\right)}
$$

where $0.017=1 / 60$, that is, the fixed cost $\left(F_{3}+F_{5}\right)$, is amortized to every month with five years as the depreciation period such that the fixed cost and the variable cost, $\left(F_{1}+F_{2}+F_{4}+F_{6}\right)$, can be unified. Obviously, high value of $F$ means high feasibility of the plan.

\subsubsection{Correlation variables}

The process of calculating the unknown variables based on the known variables inevitably involves several influencing factors, such as warehouse area, number of staff, and number of forklifts. These data can be obtained based on independent variables. Therefore, they are not major influencing factors of the model. For convenience of illustration, the following part describes only the abovementioned three types of parameters.

\subsubsection{Parametric significance}

Constants stand for management modes or management grades of branch warehouses; independent variables are the main factors that influence the grading results of branch warehouses; dependent variables are decided by independent variables and constants, and are factors primary considered in branch warehouse grading. The model built in this paper determines the law guiding the correlation between independent variables and the optimal management grade. If the optimal management grade can be obtained according to a group of independent variable data, then the data composed of tens of thousands of independent variable groups can generate tens of thousands of corresponding correlations. By using the linear regression data analysis method, certain law behind these data can be determined.

\subsection{Mapping construction}

A mapping, $f$, must be constructed such that the corresponding dependent variable, $F$, can be derived through the mapping based on independent variables and constants. Then,

$$
F=f(w, x, y, z, 1 / 2 / 3)
$$

A total of 22 groups of historical data samples were used in this research, including branch warehouse grading results obtained through subjective experiences. However, historical data are insufficient to construct such a mapping. The mapping construction is also difficult to achieve through the conventional mathematical model. Thus, the discrete event simulation model must be adopted to finish the mapping construction.

In the simulation model or the mapping $f$, the input variables include independent variables and constants, and the output variables are the corresponding dependent variables, $F$. Accordingly, the correlation among the three types of parameters can be obtained.

\subsection{Mapping verification}

Following the method of Ian Ayres [18], practical data were required to verify the feasibility of the simulation model, $f$. The simulation model, , was used to obtain the $F$ value of 22 groups of historical data samples. The model was also used to grade branch warehouses accordingly. The grading results were compared with the practical situations. Large differences between the two suggest that the simulation model must be rectified to be in line with the practical system. Only after rectification can the model start the subsequent operation.

\subsection{Simulation experiment}

In this research, Flexsim was adopted for simulation modeling. Based on the experimenter provided by the software, the simulation experiment was conducted. Independent variables were divided into several segments based on experiences. The critical values between different 
segments were integrated to create multiple experimental plans. The experimental data obtained were thus adopted as bases for data analysis.

\subsection{Formula confirmation}

For the convenience of expression, let

$$
\begin{aligned}
& F_{1}=f(w, x, y, z, 1), \\
& F_{2}=f(w, x, y, z, 2), \\
& F_{3}=f(w, x, y, z, 3),
\end{aligned}
$$

$F_{1}, F_{2}$, and $F_{3}$ stand for the $F$ value corresponding to different management modes. Under a given value of independent variables, the optimal management grade with the maximum value $F$ can be judged according to simulation data. Based on the maximum $F$ value, the corresponding grading result can be chosen. Thus, a mapping relation can be obtained as follows:

$$
g\left(\operatorname{Max}\left(F_{1}, F_{2}, F_{3}\right)\right)=\left\{\begin{array}{l}
1 \\
2 \\
3
\end{array}\right.
$$

Based on Eqs. (4), (5), (6), and (7), the independent variables of mapping (7) are still $w, x, y$ and $z$. On the basis of the simulation data, the correlation between independent variables and the grading results, namely, 1 , 2 and 3 can be obtained. In other words, the model inferring the grading results based on independent variables is obtained.

\section{Result Analysis And Discussion}

\subsection{Simulation modeling}

Figure.1 shows the simulation model built based on Flexsim, where the red goods are of Category $A$; the green goods are of Category $B$; and the blue goods are of Category $\mathrm{C}$. The stock area is simulated in the floor storage mode of Rack. The goods stack form is simulated according to two instructions in Rack, "Place in Bay," and "Place in Level," as well as the maximum capacity of every storage position.

The construction process of the simulation model is the difficult point of the model of e-commerce cloud warehouse grading. Given that the universality, flexibility, and effectiveness of the model must be guaranteed, the simulation modeling must follow certain modeling strategy, including present situation investigation, improvement plan investigation, simulation modeling, and analysis of simulation results [15].

The simulation model is highly flexible. It can automatically modify the warehouse area and the number of staff members according to the stock quantity, or transfer a proper number of forklifts or operators in line with plan requirements. Only in this way can the universality of the simulation model be guaranteed. This procedure is also the linchpin to achieve a feasible model of e-commerce cloud warehouse grading.

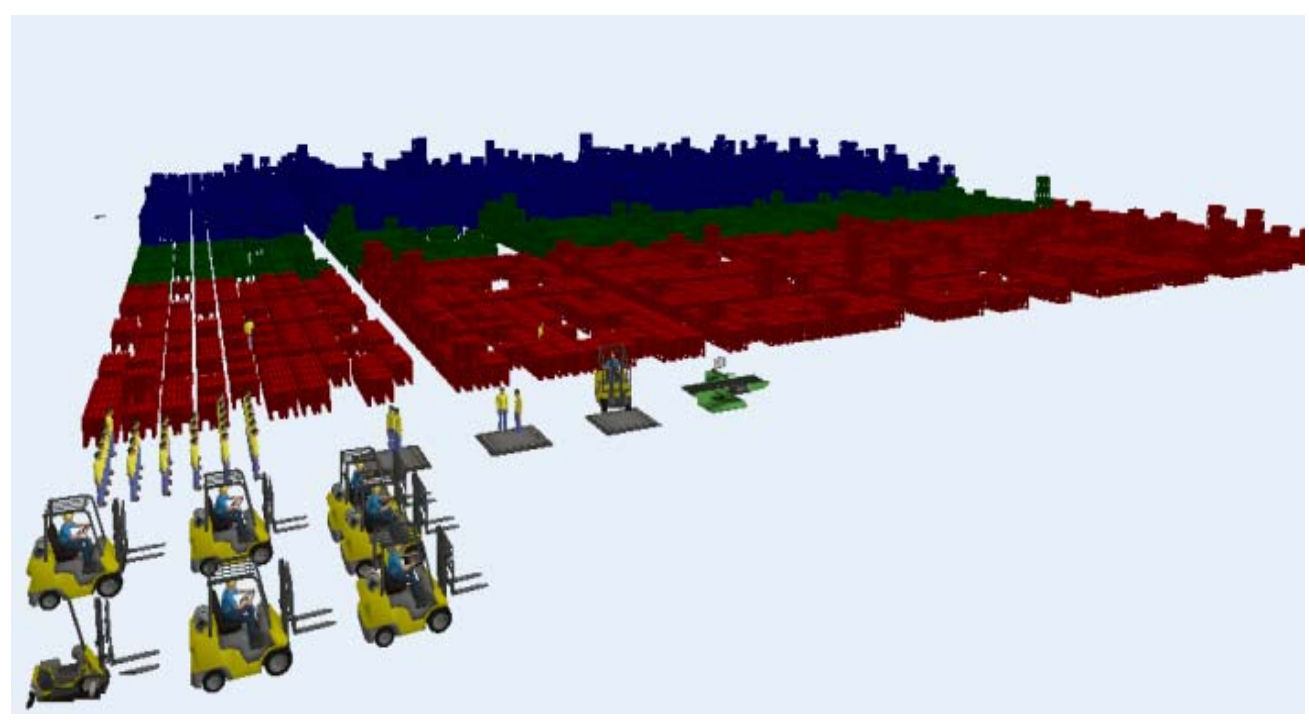

Figure $1.3 \mathrm{D}$ view of the simulation model

\subsection{Verification of the simulation model}

The stock quantity, warehouse-out quantity, local average staff member salary, and unit land rental of current branch warehouses of Group A were obtained through investigation. These data were input into the simulation model to obtain the $F$ value of the three plans. The calculation results are shown in Table.1.
Table.1 ranks the warehouse-out quantity in an ascending sequence. The scatter diagram (Figure.2) was created on the basis of the $F$ value under three different plans. Considering the influence of random factors, the law reflected by the scatter diagram is insignificant. To reflect similarly, the value of different plans underwent binomial fitting. Three curves were then obtained, as shown 


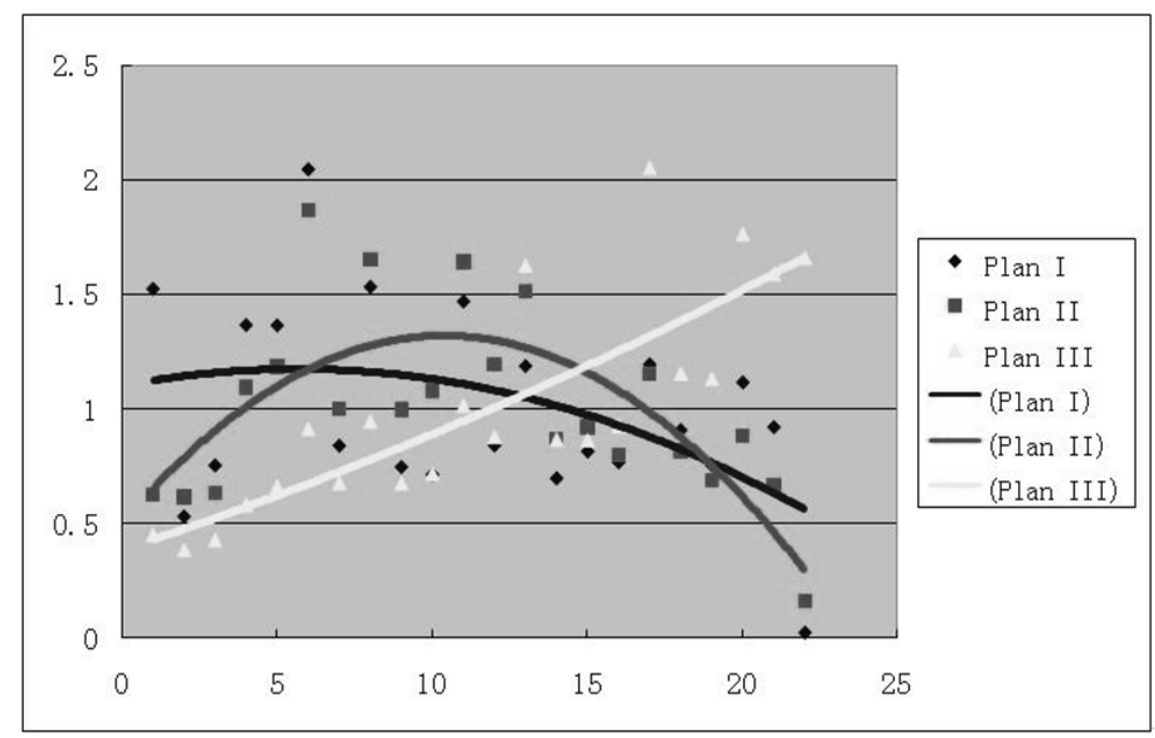

Figure 2. Scatter diagram and binomial fitting of simulation results of different branch warehouses

in Figure.2. They can vividly show the demarcations of the three plans.

The current branch warehouses can be graded based on the demarcations of the binomial curves. Plan 1 is applicable to the left part where the black line is the highest; Plan 2 is applicable to the middle part where the gray line is the highest; and Plan 3 is applicable to the right part where the white line is the highest. The results obtained are shown in Table.2.
Table. 3 shows the results of practical warehouse grading. The simulation results are in line with the practical situations. Only the grading of four branch warehouses in bold is inconsistent with practical situations. According to the feedback of Group A, the grading of Warehouse 7 and Warehouse 18 is slightly high. The grading of Warehouse 10 and Warehouse 11 is based on possibilities of rises in staff member salary and land rental. Thus, the effectiveness of the simulation model is confirmed.

\begin{tabular}{|l|c|c|c|c|c|c|c|}
\hline $\begin{array}{l}\text { Branch } \\
\text { warehouses }\end{array}$ & $\begin{array}{c}\text { stock } \\
\text { quantity } \\
\text { (Pallet) }\end{array}$ & $\begin{array}{c}\text { warehouses -out } \\
\text { peak } \\
\text { (piece/day) }\end{array}$ & $\begin{array}{c}\text { average staff member } \\
\text { salary (RMB/ } \\
\text { month/person) }\end{array}$ & $\begin{array}{c}\text { Unit land rental } \\
\text { (RMB/month/ } \\
\text { square meters }\end{array}$ & Plan 1 & Plan 2 & Plan 3 \\
\hline warehouse22 & 500 & 20653 & 2540 & 15.0 & 1.526 & 0.629 & 0.425 \\
\hline warehouse20 & 732 & 29548 & 3310 & 30.0 & 0.529 & 0.619 & 0.385 \\
\hline & & & $\ldots \ldots .$. & & & & \\
\hline warehouse2 & 2770 & 237208 & 4200 & 15.0 & 1.117 & 0.885 & 1.766 \\
\hline warehouse1 & 3949 & 299097 & 3170 & 19.5 & 0.920 & 0.669 & 1.591 \\
\hline warehouse16 & 5972 & 812792 & 3420 & 39.0 & 0.021 & 0.165 & 1.661 \\
\hline
\end{tabular}

Table.1 Schematic of practical data simulation results of various branch warehouses

\begin{tabular}{|r|c|c|c|c|c|c|c|c|c|}
\hline \multicolumn{10}{l|}{ Grade } \\
\hline 1 & warehouse & warehouse & warehouse & warehouse & warehouse & warehouse & & & \\
& 22 & 20 & 17 & 21 & 19 & 18 & & & \\
2 & warehouse & warehouse & warehouse & warehouse & warehouse & warehouse & warehouse & warehouse & warehouse \\
& 15 & 14 & 12 & 13 & 5 & 9 & 7 & 11 & 10 \\
3 & warehouse & warehouse & warehouse & warehouse & warehouse & warehouse & warehouse & & \\
& 6 & 4 & 8 & 3 & 2 & 1 & 16 & & \\
\hline
\end{tabular}

Table 2. Results of branch warehouse grading based on simulation results

\subsection{Simplification of variables}

After verifying the effectiveness of the simulation model, the simulation experiment was conducted. The value scope of independent variables was set and divided into several segments. Different independent variables were then combined to obtain multiple groups of experimental plans. In this part, the experiment plan can be simplified and the accuracy of value segments of independent variables can be improved by simplifying the variables. 


\begin{tabular}{|c|c|c|c|c|c|c|c|c|c|c|}
\hline \multicolumn{3}{|c|}{ Grade } & \multicolumn{8}{|c|}{ Practical suitable warehouse } \\
\hline 1 & $\begin{array}{c}\text { warehouse } \\
22\end{array}$ & $\begin{array}{c}\text { warehouse } \\
20\end{array}$ & $\begin{array}{c}\text { warehouse } \\
17\end{array}$ & $\begin{array}{c}\text { warehouse } \\
21\end{array}$ & $\begin{array}{c}\text { warehouse } \\
19\end{array}$ & & & & & \\
\hline 2 & $\begin{array}{c}\text { warehouse } \\
15\end{array}$ & $\begin{array}{c}\text { warehouse } \\
14\end{array}$ & $\begin{array}{c}\text { warehouse } \\
12\end{array}$ & $\begin{array}{c}\text { warehouse } \\
13\end{array}$ & $\begin{array}{c}\text { warehouse } \\
5\end{array}$ & $\begin{array}{c}\text { warehouse } \\
9\end{array}$ & $\begin{array}{c}\text { warehouse } \\
8\end{array}$ & & & \\
\hline 3 & $\begin{array}{c}\text { warehouse } \\
6\end{array}$ & $\begin{array}{c}\text { warehouse } \\
4\end{array}$ & $\begin{array}{c}\text { warehouse } \\
8\end{array}$ & $\begin{array}{c}\text { warehouse } \\
3\end{array}$ & $\begin{array}{c}\text { warehouse } \\
2\end{array}$ & $\begin{array}{c}\text { warehouse } \\
1\end{array}$ & $\begin{array}{c}\text { warehouse } \\
16\end{array}$ & $\begin{array}{c}\text { warehouse } \\
7\end{array}$ & $\begin{array}{c}\text { warehouse } \\
11\end{array}$ & $\begin{array}{c}\text { warehouse } \\
10\end{array}$ \\
\hline
\end{tabular}

Table 3. Results of practical branch warehouse grading

The investigation data show that the correlation coefficient between warehouse-out quantity and stock quantity is higher than 0.95. Therefore, the two indexes can be regarded as two consistent indexes. Data analysis shows that the grading law based on warehouse-out quantity is significant; thus, warehouse-out quantity is a suitable grading standard. Stock quantity is expressed based on warehouse-out quantity,

$$
w=0.0072 \times x+800, \quad R^{2}=0.9056
$$

instead of acting as the independent variable. Thus, the value scope of stock quantity can be ignored during experimental data design. In this way, the number of experiments can be reduced.

\subsection{Simulation experiment}

In the simulation experiment, the experimental parameters were designed. The value scope of warehouse-out quantity, average staff member salary, and unit land rental was set and combined to generate experimental parameters. A total of 10,500 groups of experimental data were obtained for the simulation experiment. Through the simulation experiment, mass simulation experimental data were obtained.

\subsection{Analysis of simulation experimental results} As shown in Figure.3, the simulation experimental results can comprehensively describe the results of the selected plan under different situations. However, utilizing these results is difficult.

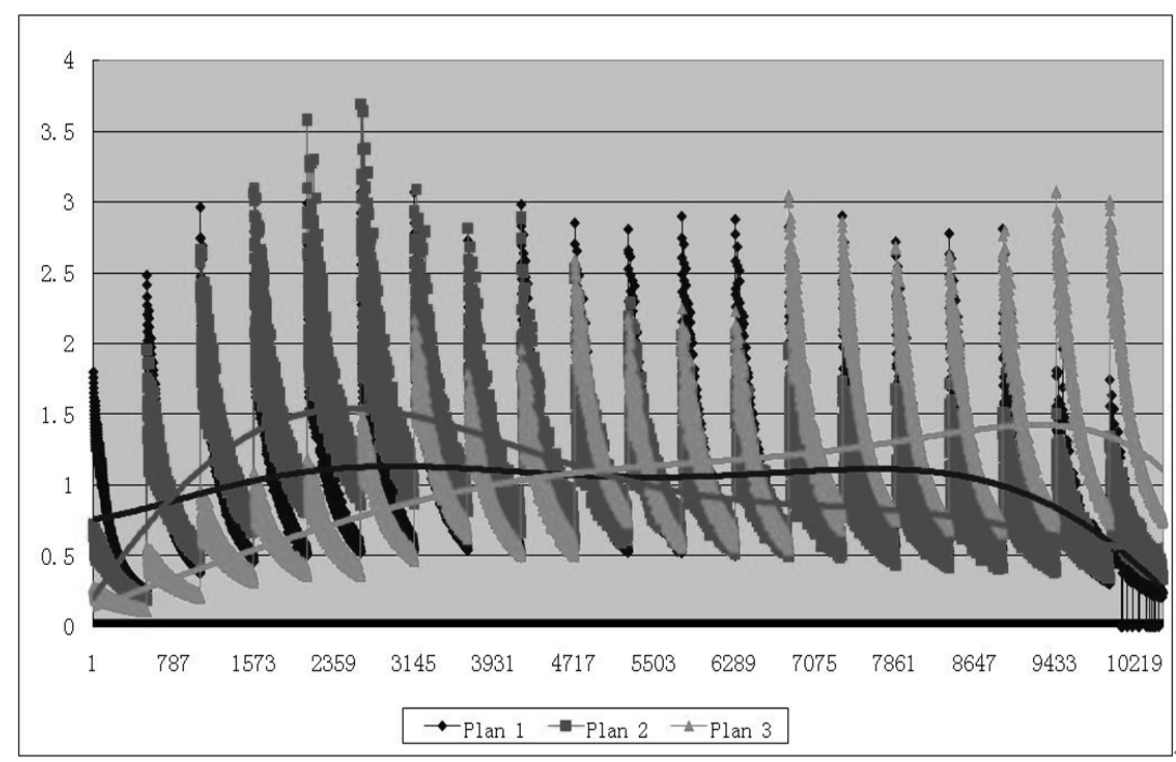

Figure 3. Comparison of the $F$ value of different plans under different experimental parameters

Figure. 3 conducts polynomial fitting of the $F$ value, but the fitting results can simply serve as bases to observe tendencies instead of bases for cloud warehouse grading. Figure. 4 adopts the plan with the maximum value under every experimental parameter as the selected plan, but Figure.4 only describes a general correlation between warehouse-out quantity and the selected plan. A few isolated points are observed, which are caused by the combined influence of salary and land rental. Obviously, Figure. 4 cannot be adopted as the basis for e-commerce cloud warehouse grading.

\subsection{Data fitting}

The multiple linear regression fitting method was adopted to describe the law of experimental results. Given that the warehouse design must meet the peak period demands, the peak value of warehouse-out quantity instead of its average value must be considered. Assuming that the peak value of warehouse-out quantity is $\operatorname{MAX}(x)$ and that the selected plan is $T$. The following two fitting approaches can be used to obtain the required results:

\subsubsection{Direct fitting}

The multiple linear regression fitting was adopted to directly describe the correlation between the three variables and 


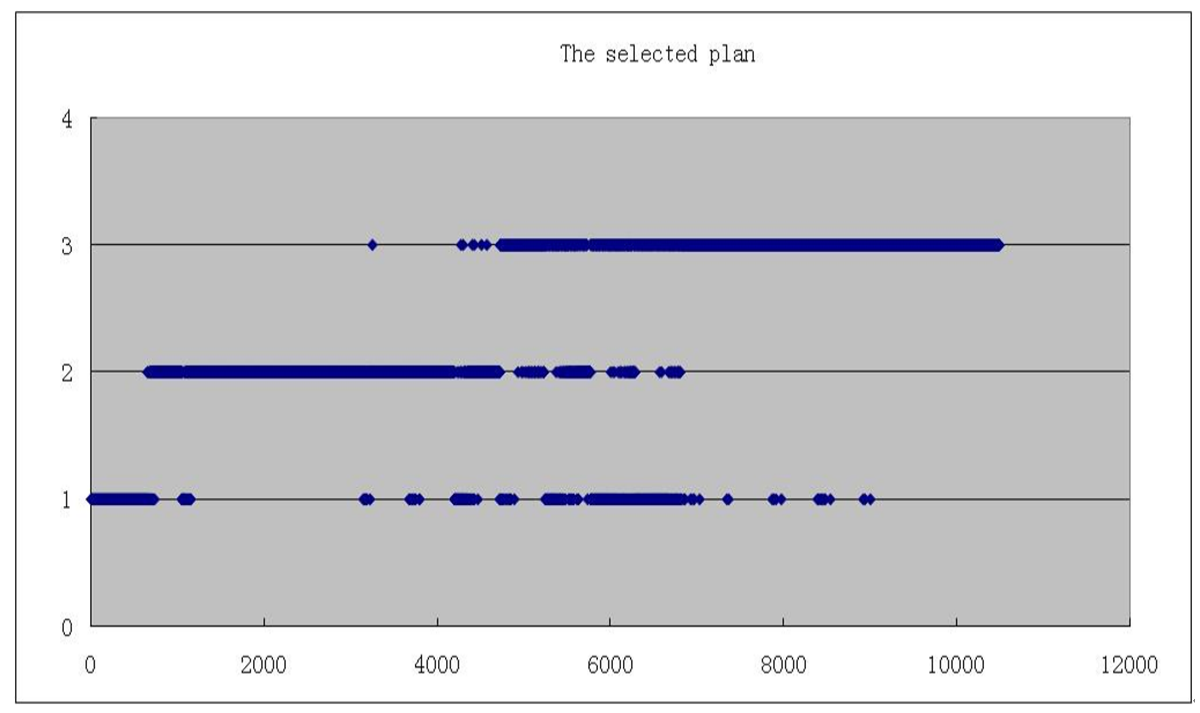

Figure 4. Selected plan directly obtained through experimental data

and the chosen plan. The following formula was obtained:

$$
\begin{aligned}
T= & \operatorname{MAX}(x) \times 4.367 \times 10^{-6}+y \times 7.277 \times 10^{-5} \\
& +z \times 0.005+0.973
\end{aligned}
$$

\subsubsection{Step-by-step optimization}

The $F$ value of three variables under different plans underwent the multiple linear regression fitting, and the following formulas were obtained:

$$
\begin{aligned}
F_{I}= & -0.261 \times \operatorname{MAX}(x)-111.687 \times y \\
& -27555.006 \times z+2225994.252 \\
F_{I I}= & -1.475 \times M A X(x)-123.247 \times y \\
& -19727.172 \times z+2322040.224 \\
F_{I I I}= & 3.017 \times \operatorname{MAX}(x)-55.619 \times y \\
& -23971.926 \times z+1221841.844
\end{aligned}
$$

The plan with the maximum value can be selected using the following formula:

$$
T=g\left(\operatorname{Max}\left(F_{1}, F_{2}, F_{3}\right)\right)=\left\{\begin{array}{l}
1 \\
2 \\
3
\end{array}\right.
$$

Considering that the two fitting approaches complete each other's advantages, they were integrated to form a final model.

\subsection{Model integration}

The experimental results of the existing data show that direct fitting can well explain Plan 1 ; step-by-step optimization can well explain Plan 2 and Plan 3. The above two plan selection approaches were combined for modeling. Direct fitting was applied to confirm Plan 1, while step-by-step optimization was applied to confirm Plan 2 and Plan 3. Consequently, the "suitable plan calculation tool" or the final model of e-commerce cloud warehouse grading was obtained.

The annual warehouse-out quantity, average staff member salary, and unit land rental of current branch warehouses can be substituted into the model to derive the suitable warehousing plan for each branch warehouse.

\subsection{Verification of the model of e-commerce cloud warehouse grading}

The model of e-commerce cloud warehouse grading was applied to Group A. The annual warehouse-out quantity, average staff salary, and unit land rental of various warehouses shown in Figure.1 were substituted into the model to obtain quantitative grading results. These results were compared with the current experience-based grading results of Group A (Table.4).

Comparison results show that, apart from four warehouses already discussed in Section 4.2, the quantitative grading results and the practical grading results of Warehouse 6 , Warehouse 4, and Warehouse 8 are also inconsistent. Among them, the quantitative grading result of Warehouse 8 is close to Plan 3. According to the feedback of Group $A$, the practical grading of Warehouse 6 and Warehouse 4 aims at keeping room for future development. Thus, the calculation results of the model of e-commerce cloud warehouse grading are in line with the practical situations. Moreover, the model can support the warehouse management decision making of Group A.

The total quantity of experimental data was controlled to check the controllability of the model and maintain its effectiveness. Although the data used did not reach the big data level, the experiment was based on the idea of big data processing. If the big data size must be increased, then the model is still valid.

\section{Conclusion}

The e-commerce cloud warehouse grade based on data analysis must be confirmed to make up defects of experience-based grading. Thus, the discrete event simulation was adopted to build the simulation model through 


\begin{tabular}{|l|c|c|}
\hline Branch warehouse & Practical grading & Quantitative grading \\
\hline Warehouse 22 & 1 & 1 \\
\hline Warehouse 20 & 1 & 1 \\
\hline Warehouse 17 & 1 & 1 \\
\hline Warehouse 21 & 1 & 1 \\
\hline Warehouse 19 & 2 & 1 \\
\hline Warehouse 18 & 2 & 2 \\
\hline Warehouse 15 & 2 & 2 \\
\hline Warehouse 14 & 2 & 2 \\
\hline Warehouse 12 & 3 & 2 \\
\hline Warehouse 10 & 2 & 2 \\
\hline Warehouse 13 & 3 & 2 \\
\hline Warehouse 11 & 3 & 2 \\
\hline Warehouse 7 & 3 & 2 \\
\hline Warehouse 5 & 3 & 3 \\
\hline Warehouse 9 & 3 & 2 \\
\hline Warehouse 6 & 3 & 2 \\
\hline Warehouse 4 & 3 & 3 \\
\hline Warehouse 8 & 3 & 2 \\
\hline Warehouse 3 & 3 & 3 \\
\hline Warehouse 2 & 3 & 2 \\
\hline Warehouse 1 & 3 & 2 \\
\hline Warehouse 16 & 3 & 2 \\
\hline
\end{tabular}

Table 4. Comparison of branch warehouse grading results

which mass experimental data were obtained. The calculation tool for confirming the branch warehouse grade was formulated by analyzing the mass experimental data. The main conclusions of this research are as follows:

(1) The feasibility of obtaining quantitative standards for e-commerce cloud warehouse grading based on mass simulation experimental data is proven. The modeling procedures include building a valid discrete event simulation model; designing the simulation experiment to obtain the mass experimental results; analyzing and integrating experimental results to obtain the model of ecommerce cloud warehouse grading; and finally, verifying the grading model.

(2) Given that obtaining different grading results is computationally costly and the extreme situations cannot be deployed, the possibility of obtaining historical data for modeling in the real world is nearly zero. Thus, the discrete event simulation is an efficient approach to obtain such kind of data.
This study also presents a few limitations. The developed simulation model must simulate different types of branch warehouses. Thus, the model must be highly flexible. To the end, various branch warehouses are abstracted and simplified. As a result, some noises exist on the simulation results. The experimenter may also stop halfway, thereby requiring manual processing. These areas can be improved by future studies.

\section{References}

[1] Negru, C., Pop, F., Mocanu, M., Cristea, V. (2016). Cost-aware cloud storage service allocation for distributed data gathering. In: 20th IEEE International Conference on Automation, Quality and Testing, Robotics (AQTR 2016), p. 1-5. Cluj-Napoca, Romania: Institute of Electrical and Electronics Engineers Inc., May. 2016.

[2] Strubytskyi, R. (2016). Organization of cloud storage data in distributed systems. In: 13th International Conference on Modern Problems of Radio Engineering, Telecommunications and Computer Science (TCSET 
2016), p. 463-467. Lviv-Slavsko, Ukraine: Institute of Electrical and Electronics Engineers Inc., February. 2016.

[3] Dokeroglu, T., Sert, S. A., Cinar, M. S., Cosar, A. (2014). Designing Cloud Data Warehouses using Multiobjective Evolutionary Algorithms. In: Proceedings of the 6th International Conference on Agents and Artificial Intelligence (ICAART 2014), p. 571-576. Angers, France: ESEO, March. 2014.

[4] Guermazi, E., Ayed, M. B., Benabdallah, H. (2015). Adaptive security for Cloud data warehouse as a service. In: 2015 IEEE/ACIS 14th International Conference on Computer and Information Science (ICIS 2015), p. 647650. Las Vegas, USA: IEEE, June. 2015.

[5] Abdelaziz, E., Mohamed, Q. (2015). Optimisation of the queries execution plan in cloud data warehouses. In: Proceedings of the 2015 5th World Congress on Information and Communication Technologies (WICT 2015), p. 129-133. IEEE, June. 2016.

[6] He, J., Sheng, Y. H. (2012). On the innovative service of supply chain finance under the third party electronic marketplace - the definition of "cloud muster warehouse" (CMW). Journal of Business Economics, 32 (7) 5-13.

[7] Pan, Y. M., Tong, Y. L. (2014). The Loan Pricing Study of Supply Chain Finance Based on Cloud Muster Warehouse (CMW). Value Engineering, 33 (16) 28-31.

[8] Li, Y. R. (2016). Introduction to e-commerce logistics cloud warehouse platform in the age of "Internet +". Market Modernization, 45 (1) 25-26.

[9] Li, Y. R. (2016). China post cloud warehouse service system in "Internet +". Modern economic information, 30 (3) 336.

[10] Chen, H. T. (2015). Industry research: E-Commerce Cloud Warehouse, do you really understand?. Siilu Web. Retrieved on July 2, 2016, from http://www.siilu.com/2015 0612/137206.shtml.

[11] Zhang, J., Johnstone, M., Creighton, D. (2012). Discrete Event Simulation Enabled High Level Emulation of a Distribution Centre. In: Proceeding of 14th International Conference on Modelling and Simulation (UKSim 2012), p. 470-475. Cambridge, United kingdom: IEEE Computer Society, March. 2012.

[12] Wasusri, T., Theerawongsathon, P. (2016). An application of discrete event simulation on order picking strategies: A case study of footwear warehouses. In: 30th European Conference on Modelling and Simulation (ECMS 2016), p. 121-127. Regensburg, Germany: European Council for Modelling and Simulation, May. 2016.

[13] Bleifus, R., Spieckermann, S., Stauber, S. (2012). A case study on simulation and emulation of a new case picking system for a US based wholesaler. In: Proceedings of the 2012 Winter Simulation Conference (WSC 2012), p. 1490-1501. Berlin, Germany: IEEE, December. 2012.

[14] Gagliardi, J., Renaud, J., Ruiz, A. (2014). A simulation modeling framework for multiple-aisle automated storage and retrieval systems. Journal of Intelligent Manufacturing, 25 (1) 193-207.

[15] Wang, F., Cui, X., Hu, X. (2016). Application of system simulation in mechanical improvement of express processing center. International Journal of Simulation Systems, Science \& Techno, 17 (1) 23.1-23.6.

[16] Mayer-Schonberger, V., Cukier, K. (2013). Big Data: A Revolution That Will Transform How We Live, Work, and Think. Boston, the United States: Houghton Mifflin Harcourt. 29-97.

[17] Tu, Z., P. (2015). The Big Data Revolution. Guangxi, China: Guangxi Normal University Press. 327-351.

[18] Ian Ayres, Y. (2014). Super Crunchers: Why ThinkingBy-Numbers Is the New Way to Be Smart. Beijing, China: People Post Press. 19-62.

[19] Ma, P., Sun, X. (2015). Leveraging for big data regression. Wiley Interdisciplinary Reviews: Computational Statistics, 7(1) 70-76.

[20] Berberidis, D., Kekatos, V., Giannakis, G. B. (2016). Online Censoring for Large-Scale Regressions with Application to Streaming Big Data. IEEE Transactions on Signal Processing, 64 (15) 3854-3867.

[21] Xiaojian, H., Fangfang, W., Peipei, L. (2015). Research on the Connotation, Characteristics and Applications of Big Data of Logistics. Scientific Journal of Information Engineering, 5 (5) 144-149.

[22] Zhong, R. Y., Lan, S., Xu, C., Dai, Q., \& Huang, G. Q. (2016). Visualization of RFID-enabled shopfloor logistics Big Data in Cloud Manufacturing. The International Journal of Advanced Manufacturing Technology, 84 (1-4) 5-16. 